\title{
Article \\ Influence of Multi-Layered Structure of Vadose Zone on Ecological Effect of Groundwater in Arid Area: A Case Study of Shiyang River Basin, Northwest China
}

\author{
Haohao Cui ${ }^{1,2,3}$, Guanghui Zhang ${ }^{1}$, Jinzhe Wang ${ }^{1}$, Qian Wang ${ }^{1}$ and Xujuan Lang ${ }^{4, *}$ \\ 1 Institute of Hydrogeology and Environmental Geology, Chinese Academy of Geological Sciences, \\ Shijiazhuang 050061, China; cuihaohao@mail.cgs.gov.cn (H.C.); zhangguanghui@mail.cgs.gov.cn (G.Z.); \\ wangjinzhe@mail.cgs.gov.cn (J.W.); wqianqian@mail.cgs.gov.cn (Q.W.) \\ 2 China University of Geosciences (Beijing), Beijing 100083, China \\ 3 Key Laboratory of Groundwater Sciences and Engineering, Ministry of Natural Resources, \\ Shijiazhuang 050061, China \\ 4 School of Water Resources and Environment, Hebei University of Geosciences, Shijiazhuang 050031, China \\ * Correspondence: langlan77@163.com
}

Citation: Cui, H.; Zhang, G.; Wang, J.; Wang, Q.; Lang, X. Influence of Multi-Layered Structure of Vadose Zone on Ecological Effect of Groundwater in Arid Area: A Case Study of Shiyang River Basin,

Northwest China. Water 2022, 14, 59. https://doi.org/10.3390/w14010059

Academic Editor: Adriana Bruggeman

Received: 5 November 2021

Accepted: 24 December 2021

Published: 28 December 2021

Publisher's Note: MDPI stays neutral with regard to jurisdictional claims in published maps and institutional affiliations.

Copyright: (C) 2021 by the authors. Licensee MDPI, Basel, Switzerland. This article is an open access article distributed under the terms and conditions of the Creative Commons Attribution (CC BY) license (https:// creativecommons.org/licenses/by/ $4.0 /)$.

\begin{abstract}
The natural vegetation in arid areas of northwest China is strongly dependent on the availability of groundwater. Significantly, capillary water plays an essential role in regulating the ecological groundwater level in the multilayered structure of the vadose zone. The soil-column test and field survey in the lower reaches of the Shiyang River Basin were conducted to investigate the influence of the multi-layered structure of the vadose zone on maintaining the ecological effect of groundwater. Based on the field survey, the results show that the depth of groundwater is $3.0 \mathrm{~m}$, and the rising height of capillary water is $140 \mathrm{~cm}$. In the soil-column test, the height of the wetting front of the column was $125 \mathrm{~cm}$. During the water releasing test, the water held by the vadose zone was $182.54 \mathrm{~mm}$, which would have maintained Haloxylon's survival in a growing season. Therefore, the multi-layered structure of the vadose zone extends the ecological groundwater depth and consequently enhances the ecological function of groundwater. Importantly, with a lower groundwater level, the clay soil layer within the rising height range of the original capillary water would hold more water and maintain a higher water content for a certain period to supply surface vegetation.
\end{abstract}

Keywords: ecological groundwater level; vadose zone; multi-layered structure; capillary water; water content; soil column test; ecological effect; Shiyang River Basin

\section{Introduction}

Inland basins of northwest China have a typical continental climate, which is characterized by low precipitation and high evaporation, as well as scarce water resources. Therefore, the natural vegetation of inland basins is highly dependent on groundwater [1,2]. Groundwater depth controls water availability to vegetation and is essential for conserving groundwater-dependent ecosystems (GDEs). Once the depth of groundwater table is lower than ecological groundwater level for a long time, the natural vegetation ecosystem will lose the water supplied by groundwater through the supporting capillary zone [3]. What is worse, it will lead to natural vegetation degradation or even death and desertification [4]. Since the 1950s, because of the rapid development of the economy and society, groundwater has been over-exploited, which led to the continuous decrease of groundwater depth, exceeding the ecological groundwater level of natural vegetation in most inland basins. Hence, how to exploit and utilize groundwater reasonably and protect ecology effectively is an urgent problem to be solved in northwest China.

The ecological groundwater level has attracted worldwide attention because of the close relationship between groundwater and groundwater-dependent ecosystems (GDEs) [5-10]. 
Many concepts have been proposed to define the reasonable ranges of groundwater depth for sustaining the GDEs [11], such as critical groundwater depth [12], ecological groundwater table [13], depth-to-groundwater threshold [14], and critical groundwater level [15]. Although the literal expressions are different, these statements have the same essence concerning ecological groundwater level [16]. The influence of the ecological groundwater level on different vegetation types is different. When the groundwater depth is less than $5 \mathrm{~m}$, the diversity and richness of herbage species are significantly higher than that of shrub layer, while the diversity and richness of herbage species are lower than that of shrub layer when the groundwater depth is more than $5 \mathrm{~m}$. The ecological groundwater level is not a single value but a series of values. The threshold of ecological groundwater level suitable for different vegetation growth has been put forward by various methods [5]. For example, the interactions among groundwater, vadose zone and vegetation are discussed based on correlation analysis between the soil water content, groundwater chemical property, plant growth and the groundwater depth $[17,18]$, or by establishing distributed eco-hydrological model and HYDRUS solute transport model $[19,20]$. No matter what method is used to calculate the ecological groundwater level, the extreme ecological groundwater level should be less than the sum of the height of supporting capillary water and the depth of vegetation root system (Figure 1). As long as the root system of vegetation reaches the depth of groundwater rising through capillarity, it can continue to obtain groundwater recharge.

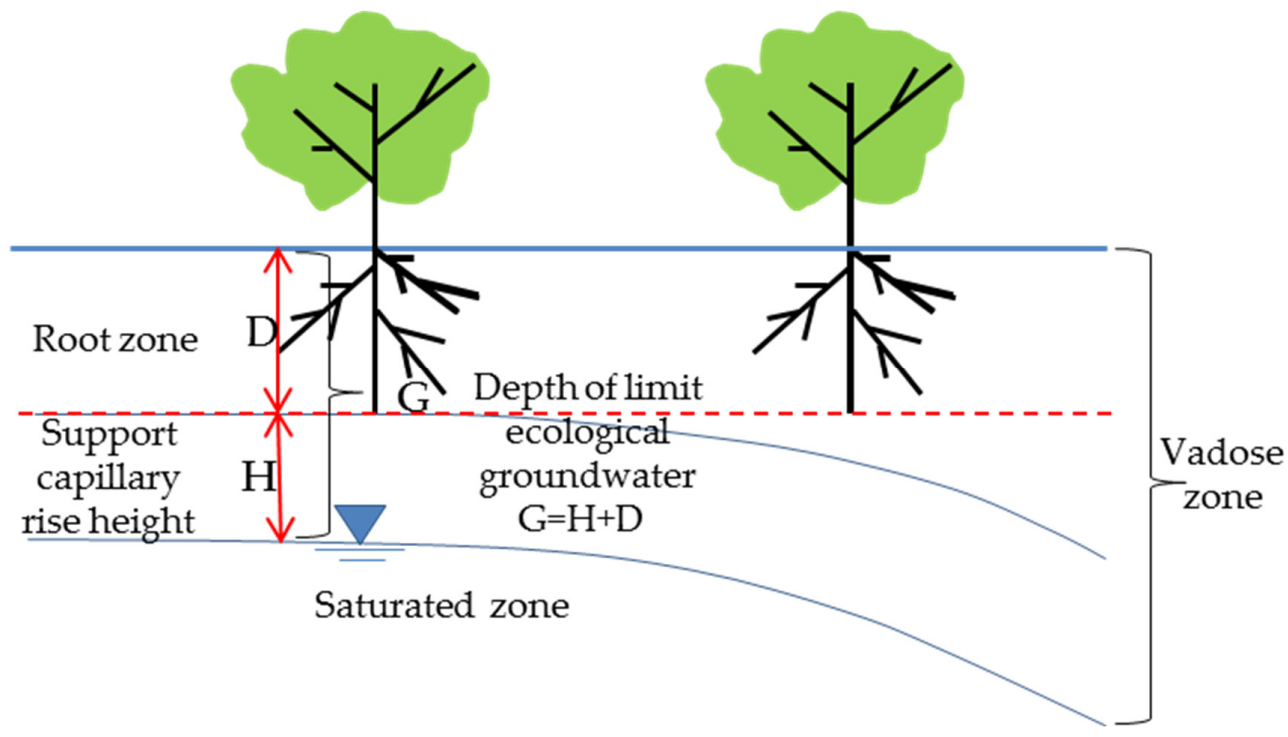

Figure 1. Mechanism of maintaining natural vegetation by supportive capillary water.

Different vegetation types have different depths of root development. Zhang et al. selected typical vegetation in an arid area of northwest China and statistically analyzed the average root development depth of tree, shrub and herb; they are $2.7 \mathrm{~m}, 2.2 \mathrm{~m}$ and $1.8 \mathrm{~m}$, respectively [21]. Sheng et al. [22] studied the root system of Haloxylon ammodendron at different ages, and the average root length is $1.4 \mathrm{~m}$ (young seedling, 1 year), $2.5 \mathrm{~m}$ (young, 4 years), $8.0 \mathrm{~m}$ (middle age, 20 years) and $13.5 \mathrm{~m}$ (40 years) separately. In addition, the root system of vegetation grows with the increase of groundwater depth to absorb the deep groundwater and keep growing. The vadose zone is a key factor connecting groundwater and surface vegetation [23]. A different structure of the vadose zone supports a different rising height of capillary water, which affects the ecological groundwater level and leads to a different ecological response of vegetation on land surface [24-27]. However, when the groundwater level drops, the release of water from pore channels with different sizes in the soil is not synchronous, which results in the delay of gravity drainage. Different vadose zones have different water-holding capacities and delayed water-releasing capacities, which lead to different effects on the growth of natural vegetation $[28,29]$. 
Scholars have made outstanding contributions to the research, as mentioned above. However, when the groundwater level drops, can the water held by the vadose zone continue to be absorbed by the roots of the vegetation? And if so, for how long? The issue is rarely discussed, but it is essential for the conservation of natural vegetation. Moreover, the results can provide more accurate data to optimize the period and volume of ecological water conveyance, which positively affects elevating the groundwater table in arid areas [30,31]. Given the above problems, this paper aims to study the influence of the multi-layered structure of the vadose zone on the ecological effect of groundwater: (1) to explore the lithological structure of the vadose zone in the typical natural vegetation area; (2) based on the exploration results, to survey pit profile, including the field test of groundwater capillary rise height; (3) to discuss the availability of water-holding capacity in the vadose zone on vegetation root water uptake by a soil-column test.

\section{Materials and Methods}

\subsection{Study Area}

The Shiyang River Basin is located in the east of Hexi Corridor in northwest China, Gansu Province, which is one of the driest regions in China. In Shiyang River Basin, the upper reaches are the Qilian mountains, the middle reaches are the corridor plains, and the lower reaches are the oasis of Minqin (Figure 2). The ecological environment of Shiyang River Basin is extremely fragile, and desertification is becoming more and more serious [32]. Minqin basin, which lies in the lower reaches of the Shiyang River Basin, is in danger of becoming the second "Lop Nur" surrounded by the Tengri and Badain Jaran deserts. It is a typical desert island, known as a "Desert Oasis". The basin geographical boundary lies between $103^{\circ} 02^{\prime} \mathrm{E}$ to $104^{\circ} 02^{\prime} \mathrm{E}$ longitude and $38^{\circ} 05^{\prime} \mathrm{N}$ to $39^{\circ} 06^{\prime} \mathrm{N}$ latitudes, and total area of the basin is $1.59 \times 10^{4} \mathrm{~km}^{2}$, in which desert and desertification area accounted for $94 \%$; oasis area only accounted for $6 \%$. The studied catchment experiences an arid-continental climate with an annual average temperature of $8.8^{\circ} \mathrm{C}$ and $3142.2 \mathrm{~h}$ of sunshine. The mean annual evaporation in the watershed is $2675.6 \mathrm{~mm}$, far exceeding the mean annual precipitation (113.2 $\mathrm{mm})$ [33].

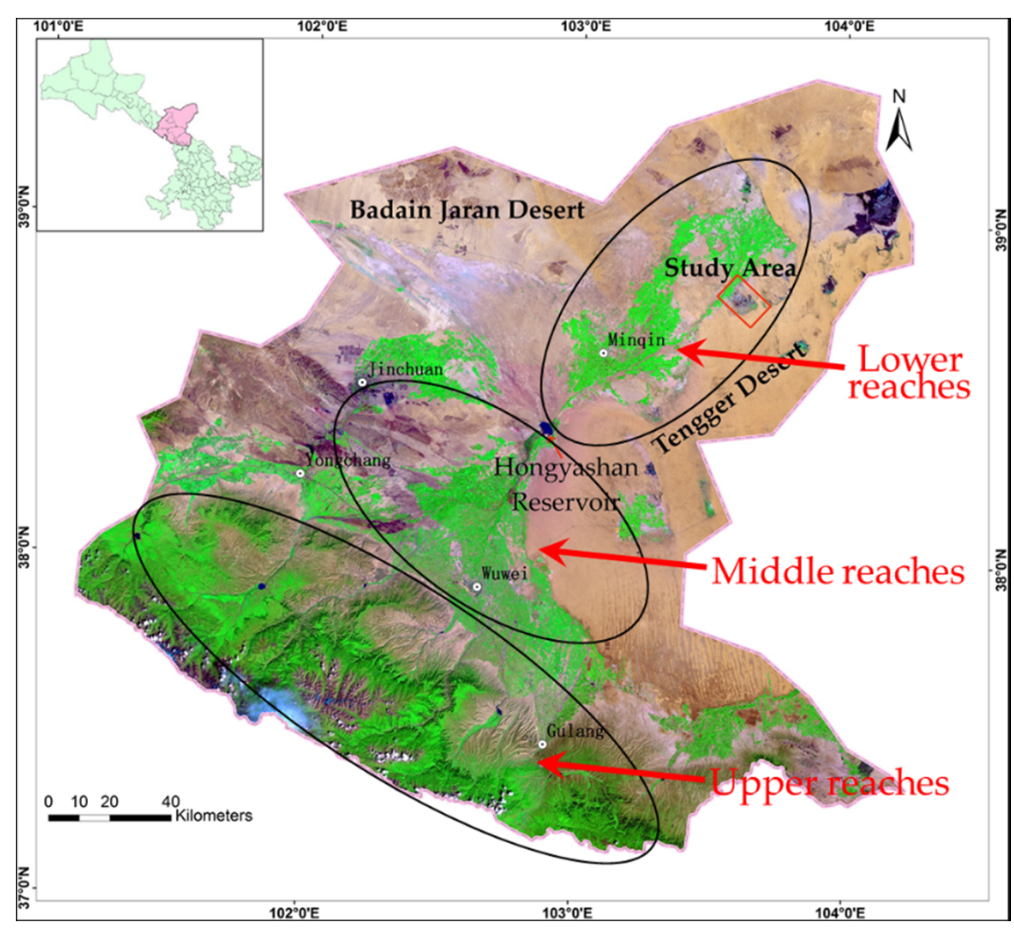

Figure 2. Remote-sensing image of the Shiyang River Basin and the study area of Minqin Basin. 
Note: The image is based on Landsat 8 data of 2019 and has been processed by radiation correction, atmospheric correction, geometric correction, image fusion and color synthesis. In the image, the green color indicates the vegetation area, including natural vegetation and farmland; the brown color indicates desert areas; the dark color indicates wetlands; the red box area is the study area; and the black oval area indicates the different positions of the upper, middle and lower reaches of the basin.

\subsection{Materials and Methods}

The field survey and soil-pit sampling (field survey) are more in line with the actual situation, but the experimental conditions cannot be controlled. While the soil-column test can control the test conditions according to the experimental purpose, the results are too ideal. Therefore, in this paper, field survey and soil-column tests were designed according to the purpose of the research, and the results of the two were compared and verified with each other. Based on the typical stratum-structure investigation, a specific area was selected to conduct the field survey, study the groundwater capillary rise height and retrieve soil samples from different stratums for soil-column tests. The result obtained by the field survey was the closest to the actual value and can be used as an accurate measure of the soil-column tests. The soil-column tests included the capillary-water rising test and the water-releasing test of the multi-layered structure of the vadose zone. The capillarywater rising test, which is the basis of the water-releasing test, aimed to study the height of groundwater capillary rise of the typical vadose zone structure, the process of water migration, and the water content of different lithological soils. The purpose of the waterreleasing test was to study: (1) whether the amount of water held by different lithological soils in the vadose zone can continue to maintain the survival of the vegetation when the depth of the local groundwater drops significantly below the ecological groundwater level, and (2) how long it will last.

\subsubsection{Field Survey}

In order to study the capillary rising height of the typical stratum structure in the natural vegetation area, the phreatic water-depth and stratum-structure drilling survey were performed in the study area in the early stage. Two survey routes were established in the natural vegetated area, and each was approximately $10 \mathrm{~km}$. At each survey line, drilling was carried out at intervals of approximately 1 to $2 \mathrm{~km}$ depending on the growth of vegetation and the change in vegetation type (Figure 3). Soil samples were taken every $20 \mathrm{~cm}$ to record soil lithology. All boreholes were manually drilled with an earthboring auger until the groundwater table and each soil lithology were analyzed for particle composition in the laboratory.

Based on the analysis and comparison of the boreholes, the pit site was chosen to be located in the natural vegetation area about $2 \mathrm{~km}$ southeast of the fifth team of Fengqing village in Minqin Basin, which is between farmland and the Tengger Desert. The pit was rectangular, digging from the ground surface to the phreatic water, of which the depth was $3.0 \mathrm{~m}$. The surrounding vegetation was mainly composed of Tamarix ramosissima, Salt claw and Black fruit Chinese wolfberry, while the pit was located near Tamarix chinensis.

The field survey was used to measure the rising height of capillary water in groundwater directly. In the excavation process, the soils of different depths and lithology were arranged in order, and about $100 \mathrm{~kg}$ of silt, clay, silty fine sand and medium-fine sand were taken back to prepare the soil-column experiment. After excavating the test pit, the field lithology was described first. The 20-30 g soil samples were taken from the section at intervals of $10 \mathrm{~cm}$ depths and placed in the aluminum box, and then 3 repeated samples were taken from each layer. The soil moisture content was measured by drying method in the laboratory. Then soil samples were taken from the section with a $100 \mathrm{~cm}^{3}$ soil sample ring every $20 \mathrm{~cm}$ depth to determine its dry bulk density. After collecting soil samples, the observation profile was covered with a shading net to avoid sun exposure and to ensure soil moisture drying under natural conditions. Repeated samples were taken again from 
the same location in the early morning 3 days later. After 3 days of natural evaporation, the water content in the upper part of the formation will be significantly reduced when measured again. In contrast, the water content in the lower part of the formation is rarely changed due to the continuous recharge by groundwater capillary. The intersection of the two curves is where the water content is significantly reduced. The water content below the intersection is basically unchanged due to the continuous recharge of groundwater capillary action. Therefore, the intersection of the two water content curves indicates the position of the height of groundwater capillary rise [24].

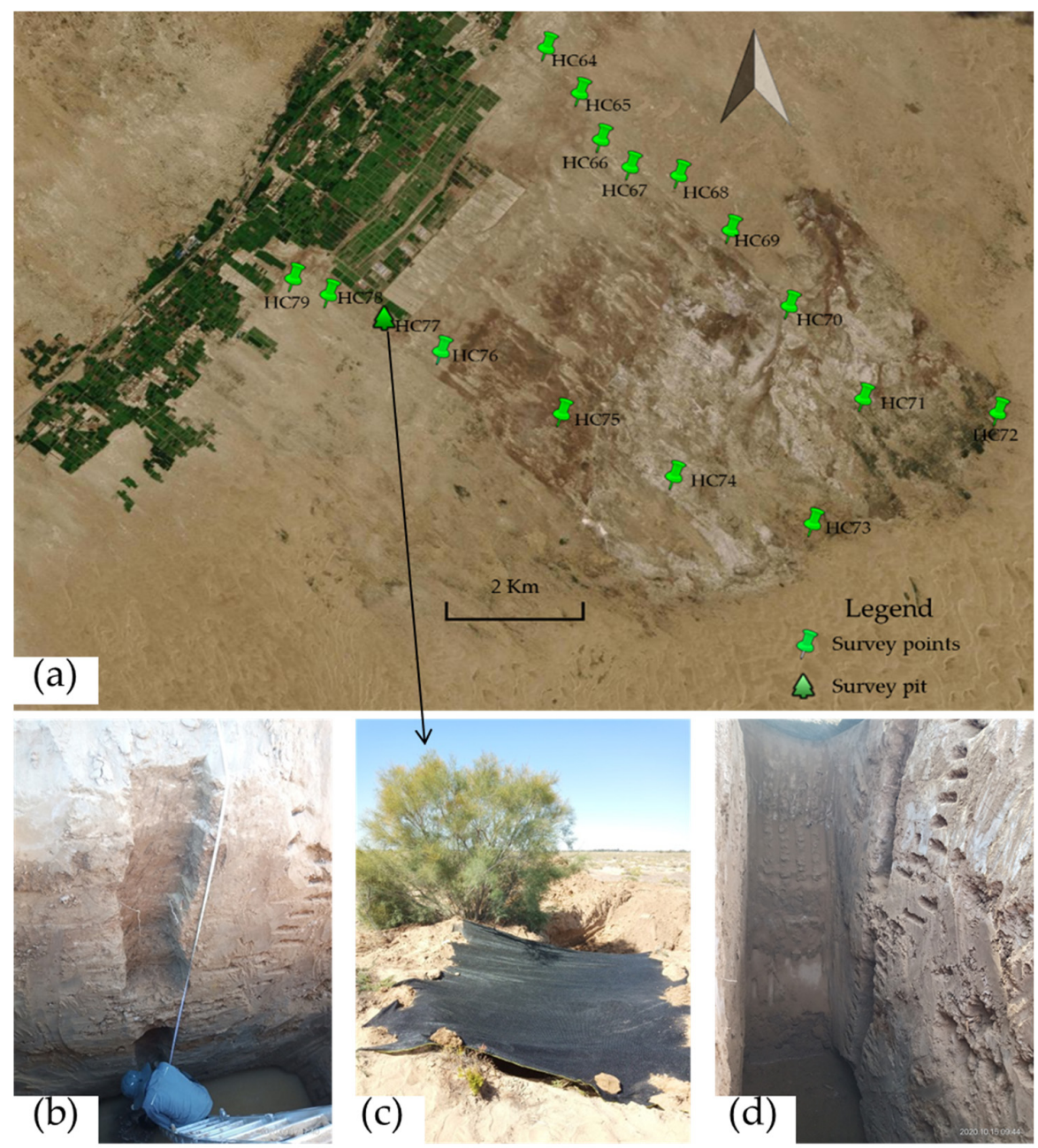

Figure 3. The location map and photos of the survey pit. (a) location map of the survey pit; (b) pit section sampling; (c) cover the shading net after sampling; (d) pit profile under the shading net.

\subsubsection{Soil-Column Tests}

In order to study the effect of the layered structure of the vadose zone on the ecological groundwater level, the laboratory soil-column tests were designed, which included the capillary water rising test and the water releasing test of the multi-layered structure of the vadose zone.

\section{(1) Instrument of Soil-Column Tests}

The instrument, made of plexiglass, was divided into a water supply device and a test device. The water supply device, Mariotte's bottle, can keep the constant water head during the water supply, and has a diameter of $20 \mathrm{~cm}$ and a height of $80 \mathrm{~cm}$. The diameter of the test device is also $20 \mathrm{~cm}$, and the height is $200 \mathrm{~cm}$. A series of sampling holes with a diameter of $2 \mathrm{~cm}$ were arranged from top to bottom at intervals of $10 \mathrm{~cm}$, and were used 
to measure the water content of soil samples during the experiment (Figure 4). Before the test, water was added to ensure the sealing effect was good. Then, soil samples were filled in layers in the test equipment. The section structure of the soil column was optimized according to the strata of the test pit. The main body of the soil column was $150 \mathrm{~cm}$. It was composed of silty soil $(40 \mathrm{~cm})$, clay soil $(40 \mathrm{~cm})$, silty fine sand $(20 \mathrm{~cm})$ and medium fine sand $(50 \mathrm{~cm})$ from top to bottom. The bottom of the soil column was coarse sand $(30 \mathrm{~cm})$ as the aquifer (Figure 4 ).
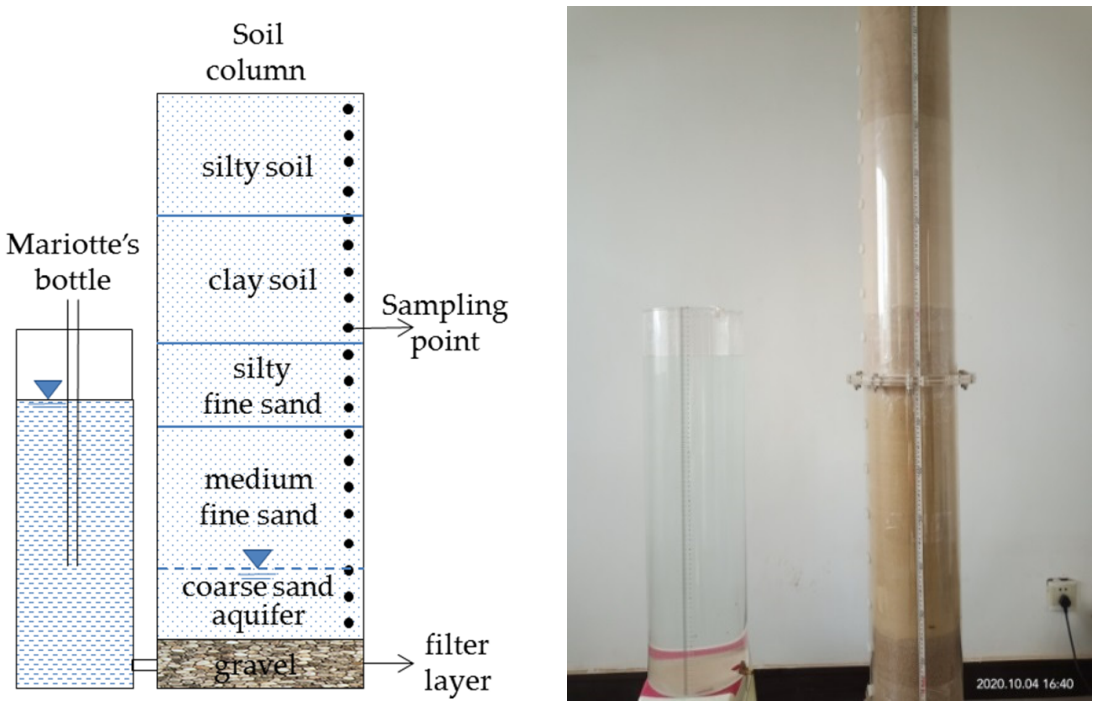

Figure 4. The structure and photograph of the test equipment.

After drying, crushing and sieving, the soil samples were filled in layers according to the original dry bulk density. Different lithological soil was separated using 100 mesh nylon screens to distinguish the soils after the experiments. The soil moisture test tube was installed in the center of the soil column to monitor the change of soil moisture in the soil-column section during the test. The bottom of the column was backfilled with small gravel of $20 \mathrm{~cm}$ thickness as a filter layer, and $30 \mathrm{~cm}$-thick coarse sand was backfilled at the top of the filter as an aquifer. The Mariotte's bottle acted as a water supply device in the capillary rising process and a drainage device in the water release process.

(2) Capillary Water Rising Test of the Multi-layered Structure of Vadose Zone

After finishing the soil backfill, the water content of the initial soil-column profile was measured by the soil-moisture meter and corrected by the fitting formula that is listed in the following section. A hose was used to connect the water tap at the bottom of the Mariotte's bottle to the bottom of the soil column, from which the Mariotte's bottle supplies water to the soil column. The water level in the soil column was determined by the water head that set in the Mariotte's bottle. When the water supply started, the coarse sand aquifer backfilled by the soil column was gradually filled, and the time started when the water level reached the set depth. During the experiment, it was necessary to record the rising position of the wetting front of the soil column and the amount of water supplied, which was expressed by the scale of Mariotte's bottle. After the wetting front of the soil column stopped rising, the moisture content of the soil-column section was measured again by the soil-moisture meter, and the soil-moisture content was measured by the drying method with a soil sample of about $20 \mathrm{~g}$ packed in an aluminum box from the sampling point.

\section{(3) Water-Releasing Test of the Multi-layered Structure of Vadose Zone}

The water-release test was the inverse process of the capillary water-rising test. The water in the Mariotte's bottle was emptied to act as a drainage device to record the water release. The entire soil began to release water freely by gravity after opening the water tap 
at the bottom of the column, and at the same time started to record the time and the amount of water entering the Mariotte's bottle. The moisture content of the whole soil-column section was measured twice a day by a soil-moisture meter, once in the morning and once in the evening. When the water in the bottle was no longer increased, the water-release test was finished.

\subsubsection{Methods}

\section{(1) Drying Method [34]}

The drying method is the most commonly used standard method for measuring soil moisture. The soil samples are dried at $105^{\circ} \mathrm{C}$ to a constant weight, at which time the soil organic matter does not decompose and the free water and hygroscopic water in the soil are entirely removed. Calculate the ratio of the water quality of the soil to the quality of the drying soil, that is, the mass water content, expressed as a percentage.

The weight of the sample container (aluminum box) is weighed by balance first, and about $20 \mathrm{~g}$ of soil sample is put into the aluminum box and weighed again. Then the aluminum box containing the soil sample is placed in an oven and dried at $105-110{ }^{\circ} \mathrm{C}$ to the constant weight (about $8 \mathrm{~h}$ ). Finally, it is taken out and cooled in the dryer for about $20 \mathrm{~min}$ and weighed immediately.

$$
\omega \%=(\mathrm{w} 2-\mathrm{w} 3) /(\mathrm{w} 3-\mathrm{w} 1) \times 100
$$

$\omega$-mass moisture content (\%); w1 - the weight of aluminum box (g); w2 - the weight of aluminum box and fresh soil (g); w3 - the weight of aluminum box and dry soil (g).

\section{(2) Dry Bulk Density [34]}

The soil-sample ring method is commonly used to measure soil-bulk density, and the soil-sample ring with a volume of $100 \mathrm{~cm}^{3}$ is usually used for sampling. Before sampling, the soil-sample ring should be weighed. When sampling, the edge of the soil-sample ring should be pressed down into the soil vertically until it is filled with samples. Cut the soil around the edge of the ring with a repair knife, carefully cut off the excess soil at both ends of the soil-sample ring, and wipe off the outside soil. At the same time, take another sample in the same layer with an aluminum box to measure the natural mass moisture content by drying method. Cover both ends of the soil-sample ring immediately to prevent water evaporation and then weigh and record. The drying method is used to measure mass moisture content,

$$
\gamma=(x 2-x 1) \times(1-\omega \%) / v
$$

where $\gamma$ is dry bulk density $\left(\mathrm{g} / \mathrm{cm}^{3}\right) ; \omega$ is mass moisture content $(\%) ; \mathrm{x} 1$ is the weight of soil-sample ring $(\mathrm{g}) ; \mathrm{x} 2$ is the weight of soil-sample ring and fresh soil $(\mathrm{g}) ; \mathrm{v}$ is volume of soil-sample ring $\left(\mathrm{cm}^{3}\right) ; \omega$ is mass moisture content $(\%)$.

The volumetric water content $(\theta)$ of the soil mentioned in this paper can be calculated from the mass moisture content and the dry bulk density of the soil.

$$
\theta=\omega \times \gamma
$$

\section{(3) Data Calibration}

The soil-moisture meter used to measure the moisture content of the soil column in this test is Trime-Pico-IPH TDR (Trime), which is made in IMKO Micromodultechnik $\mathrm{GmbH}$ (Ettlingen, Germany). Based on the time domain reflectometry with intelligent microelements, Trime can directly measure the dielectric constant of soil or other media, which is closely related to the soil moisture content. The soil moisture content can be calculated and displayed by the reading system through the output of the analog voltage. Because the calibration of Trime is carried out by the ideal medium, there are some errors for the actual testing of rock and soil, so it is necessary to use the drying method to calibrate the Trime. Based on the collected soil samples, after gradually adding water to the target 
soil sample and mixing different water content from low to high, the correlation between the data measured by Trime and the data measured by drying method is established. The data of the Trime test cannot be analyzed until they are calibrated by fitting formula.

\section{Results}

\subsection{Results of the Field Survey Soil Sample Analysis and Groundwater Depths}

The survey showed that the vadose zone was a multi-layered structure composed of silty soil, clay soil, silty fine sand and medium fine sand from surface to phreatic water. The composition and dry-bulk density of different lithological particles are shown in Table 1. The overall trend of groundwater depth decreases from northwest to southeast. As shown in Figure 5, the groundwater depth near farmland is about $3.5 \mathrm{~m}$, and that near Tengger Desert is about $2.0 \mathrm{~m}$.

Table 1. Particle composition and dry bulk density of soil samples.

\begin{tabular}{|c|c|c|c|c|c|c|c|}
\hline \multirow{2}{*}{ Lithology } & \multicolumn{6}{|c|}{ Percentage of Different Soil Particles (\%) } & \multirow{2}{*}{$\begin{array}{l}\text { Dry Bulk Density } \\
\qquad\left(\mathrm{g} / \mathrm{cm}^{3}\right)\end{array}$} \\
\hline & $>1 \mathrm{~mm}$ & $1-0.5 \mathrm{~mm}$ & $0.5-0.25 \mathrm{~mm}$ & $0.25-0.1 \mathrm{~mm}$ & $0.1-0.075 \mathrm{~mm}$ & $<0.075 \mathrm{~mm}$ & \\
\hline silty soil & 0 & 0 & 0.04 & 47.78 & 20.82 & 31.36 & 1.35 \\
\hline clay soil & 0.23 & 4.65 & 3.14 & 29.17 & 28.98 & 33.84 & 1.44 \\
\hline silty fine sand & 0 & 0.24 & 17.88 & 53.90 & 15.32 & 12.66 & 1.51 \\
\hline medium fine sand & 0.01 & 16.85 & 26.93 & 33.40 & 14.85 & 7.96 & 1.60 \\
\hline
\end{tabular}

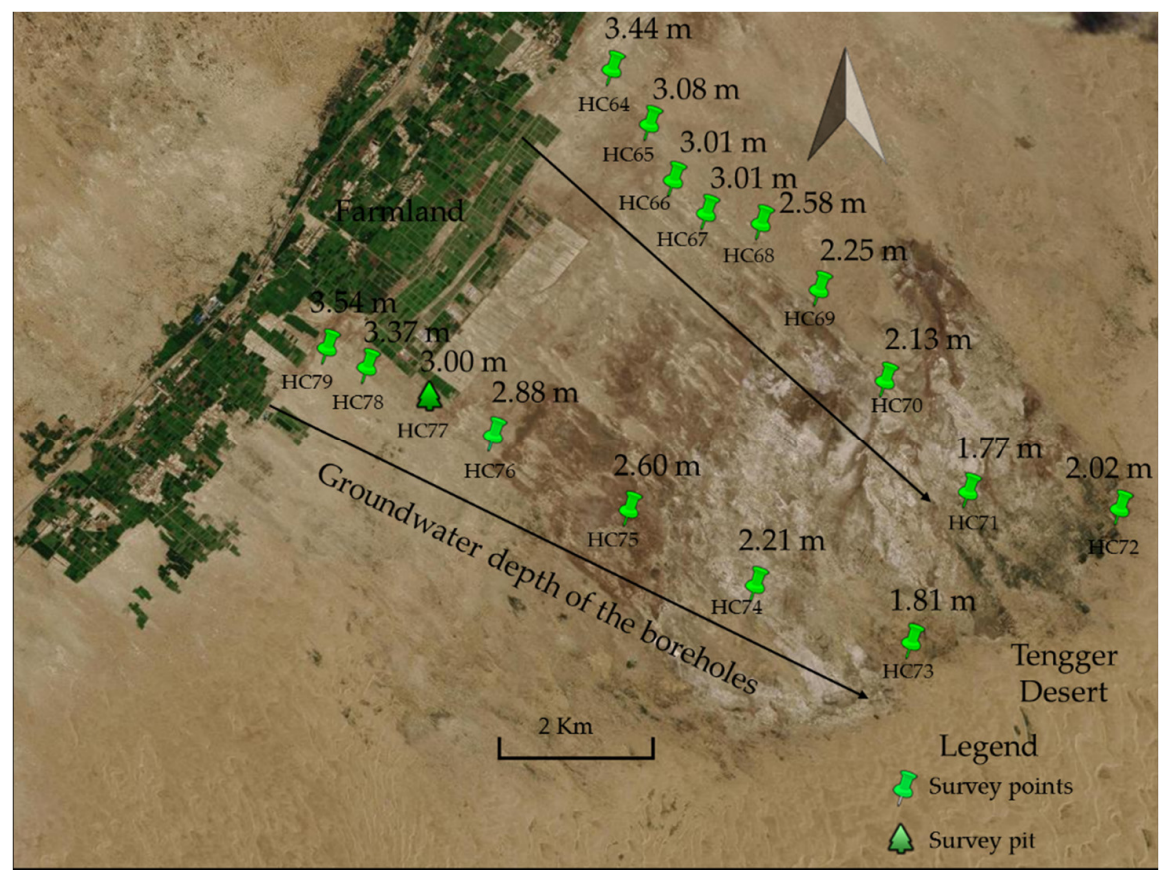

Figure 5. Groundwater depths of the boreholes.

\subsection{Calibration Results}

It can be seen from Figure 6 that the fittings of all the soil are good, among which the silty soil calibration formula is $y=1.9577 x+0.0149, R^{2}=0.9698$, the clay soil calibration formula is $\mathrm{y}=1.6073 \mathrm{x}+0.0243, \mathrm{R}^{2}=0.9536$, the silty fine sand calibration formula is $y=1.984 x-2.0331, R^{2}=0.9811$, and the calibration formula of medium fine sand is $y=1.0885 x+0.6578, R^{2}=0.9948$. 

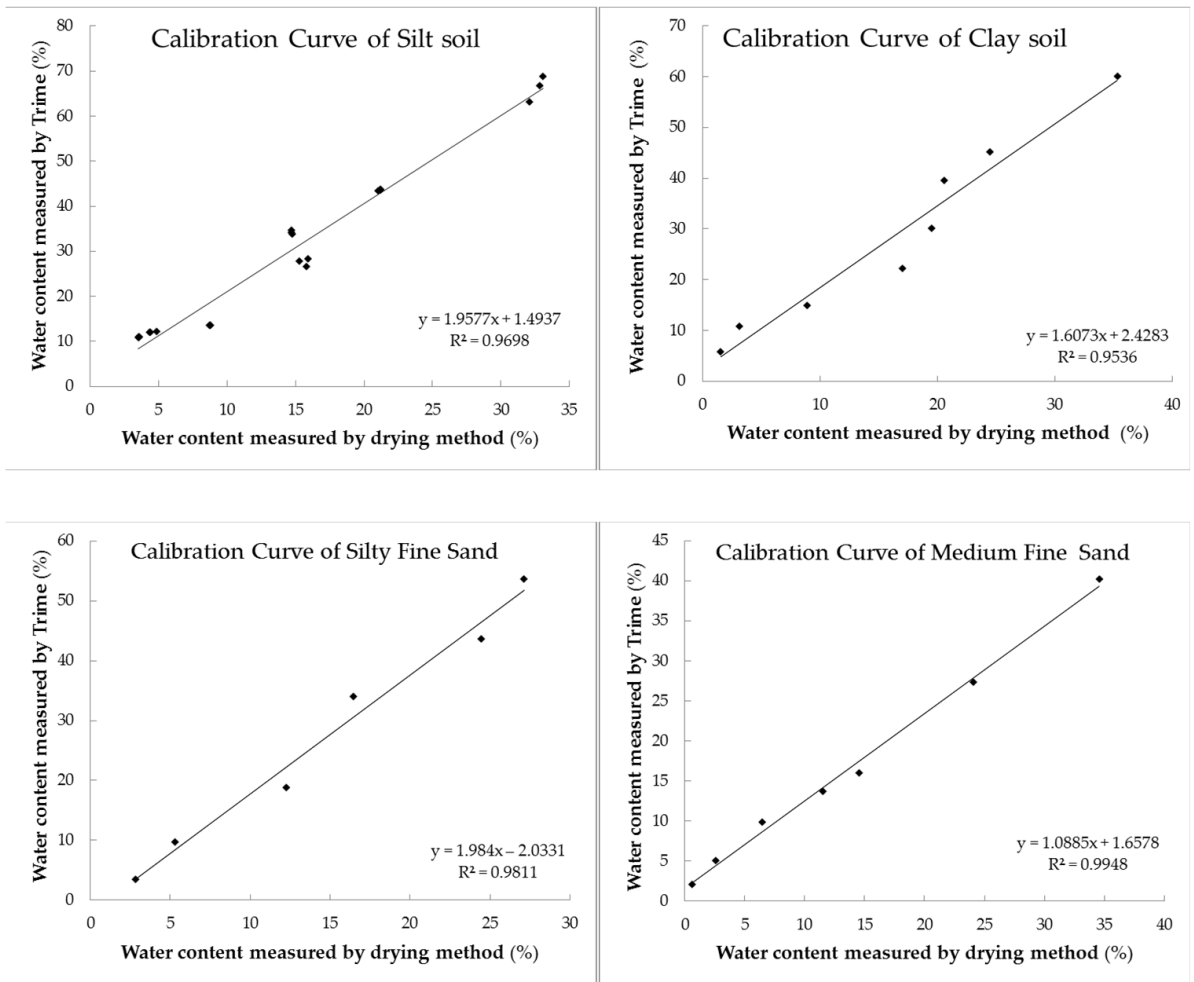

Figure 6. Calibration curve of different lithological soil filled in the column.

The data tested by the Trime were recalibrated by the above fitting formulas and then used for the calculation in the paper.

\subsection{Capillary Water Rising Height of Typical Stratum Structure in Natural Vegetation Area}

By comparing the soil-moisture curves drawn from the profile, it can be concluded that the 2 curves have an obvious intersection point at a depth of $160 \mathrm{~cm}$ from the surface (Figure 7). The soil moisture content of the stratum above the intersection decreased obviously after 3 days of drying, while the continuous recharge moisture content of the stratum below the intersection was little changed. It can be concluded that the depth of the point was $140 \mathrm{~cm}$, which indicated the capillary rising height of the groundwater. In the field investigation, a large number of calcareous nodules were found in the silty soil at a depth of 60-170 cm, the existence of which may lead to larger pores in the soil, thus blocking the capillary rise of groundwater.

As shown from Figure 6, the overall trend of soil-moisture content decreases with the increase of capillary water height in the whole range of capillary water height, which shows that the capillary-water holding capacity decreases above the water level. Only about $20 \mathrm{~cm}$ above the water level can maintain a higher soil moisture content. We found that $180-220 \mathrm{~cm}$ of the test pit profile had the lowest soil-water content, about $10 \%$, due to the silty fine sand with loose and uneven soil particles.

\subsection{Capillary Water Rising Process in Layered Vadose Zone}

The soil-column test began on 4 October 2020, and ended on 17 October 2020, with a cumulative running time of $317.45 \mathrm{~h}$. During the test, the cumulative water supply of the Mariotte's bottle was $297 \mathrm{~mm}$, and the cumulative height of the wetting front of the soil column was $112.6 \mathrm{~cm}$ (Figure 8). The total amount of water supplied to the soil column was $291.28 \mathrm{~mm}$ (Table 2), calculated from the soil moisture content measured by the drying method, which was basically consistent with the water supplement record of the Mariotte's bottle. 
In the range of $0-80 \mathrm{~cm}$, the wetting front increased rapidly, at about $1.6 \mathrm{~cm} / \mathrm{h}$, and then the ascending speed decreased to $0.12 \mathrm{~cm} / \mathrm{h}$ during the following time. According to the scatter plot of cumulative height of wetting front with the time, the relationship was in accordance with logarithmic function, $\mathrm{y}=14.798 \ln (\mathrm{x})+22.762, \mathrm{R}^{2}=0.9689$ (Figure 8).

As shown from Figure 9, the distribution of water content is different obviously from the groundwater level to max height of the capillary rise, and the height of the saturatedwater content zone maintained by groundwater level is only about $15 \mathrm{~cm}$. The water content of silt and clay soil is higher than that of sand soil, and the composition and structure of soil particles directly impact the water content. From the water-content distribution, it can be seen that the capillary-rise height of groundwater is $125 \mathrm{~cm}$, which is slightly higher than the height of the wetting front $(112.6 \mathrm{~cm})$, which is observed visually, and the observation error is inevitable.

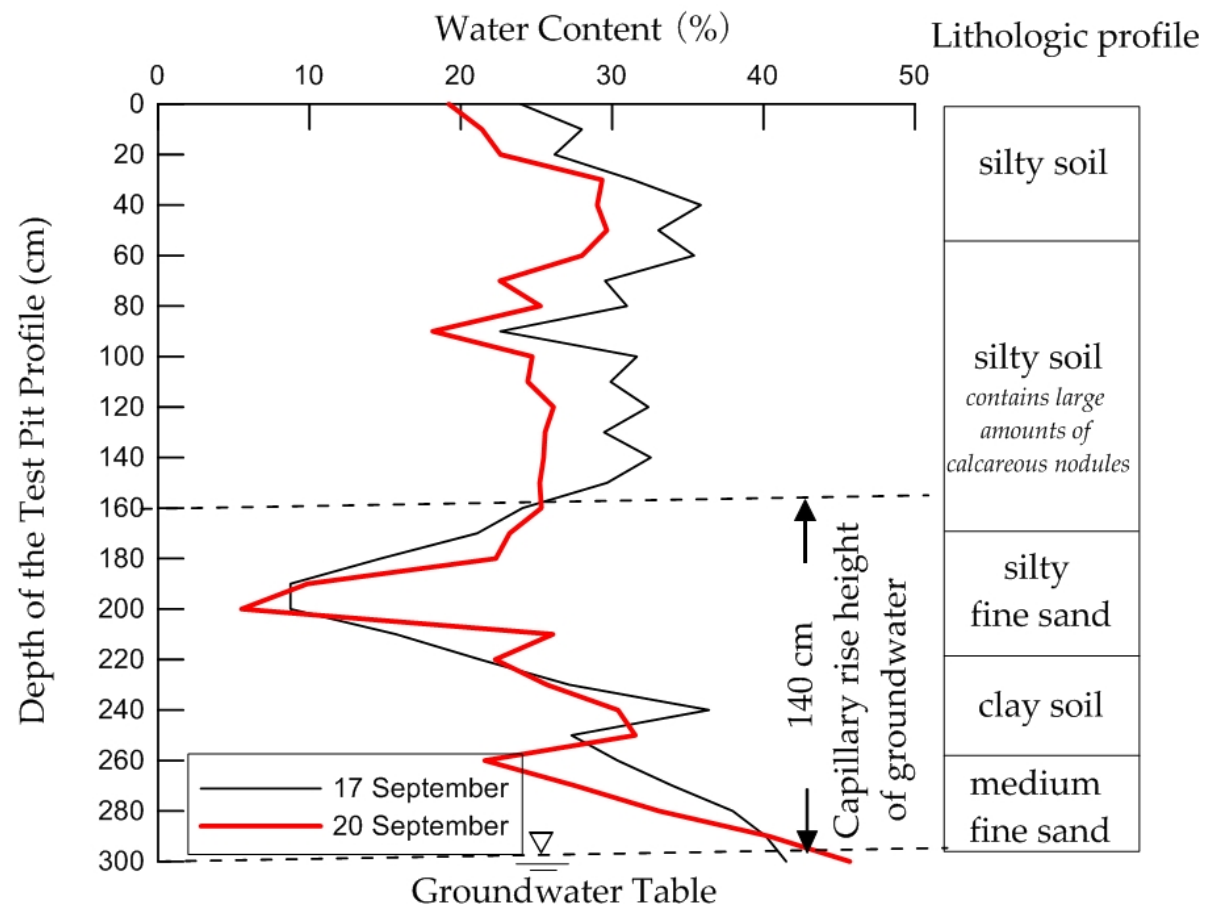

Figure 7. Capillary rise height of groundwater measured by in situ pit test.
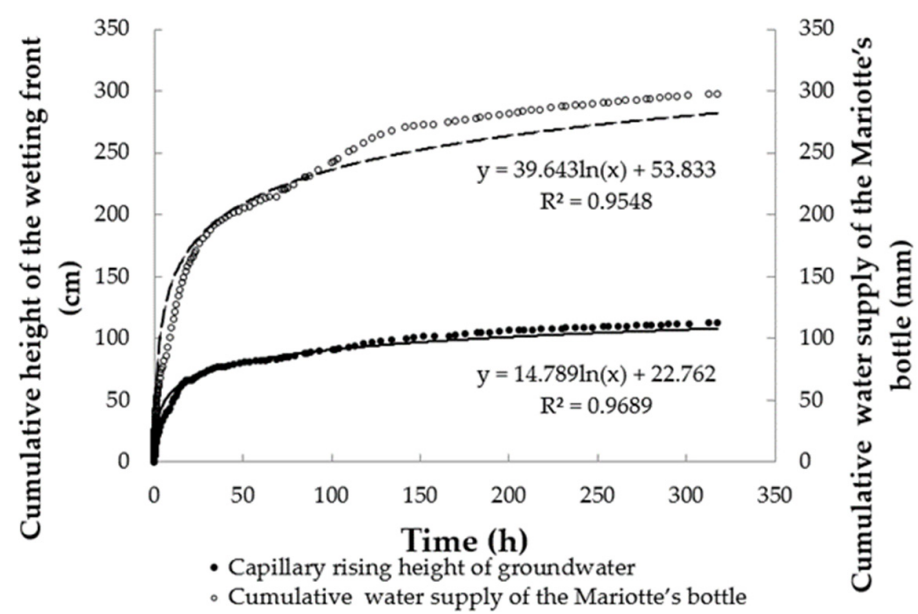

Figure 8. Cumulative height of wetting front and the cumulative water supply increasing with time. 
Table 2. The total amount of water supplied to the soil column during the capillary-water rising experiment.

\begin{tabular}{|c|c|c|c|c|c|}
\hline Testing Depth (cm) & Lithology & $\theta_{\text {final }}(\%)$ & $\theta_{\text {initial }}(\%)$ & $\theta_{\text {final }}-\theta_{\text {initial }}(\%)$ & $\Delta W(\mathrm{~mm})$ \\
\hline 5 & Silty soil & 6.41 & 6.69 & - & - \\
\hline 15 & Silty soil & 7.47 & 6.69 & 0.78 & 0.78 \\
\hline 25 & Silty soil & 7.21 & 6.69 & 0.51 & 0.51 \\
\hline 35 & Silty soil & 17.52 & 6.69 & 10.83 & 10.83 \\
\hline 45 & Clay soil & 29.76 & 1.54 & 28.22 & 28.22 \\
\hline 55 & Clay soil & 32.17 & 1.54 & 30.63 & 30.63 \\
\hline 65 & Clay soil & 32.95 & 1.54 & 31.41 & 31.41 \\
\hline 75 & Clay soil & 34.16 & 1.54 & 32.62 & 32.62 \\
\hline 85 & Silty fine sand & 26.09 & 0.26 & 25.83 & 25.83 \\
\hline 105 & Medium fine sand & 18.71 & 0.58 & 18.13 & 18.13 \\
\hline 115 & Medium fine sand & 21.96 & 0.58 & 21.38 & 21.38 \\
\hline 125 & Medium fine sand & 28.59 & 0.58 & 28.01 & 28.01 \\
\hline 135 & Medium fine sand & 32.35 & 0.58 & 31.77 & 31.77 \\
\hline \multirow[t]{2}{*}{145} & Medium fine sand & 31.74 & 0.58 & 31.17 & 31.17 \\
\hline & & umulativ & pply (mm) & & 291.28 \\
\hline
\end{tabular}

Testing Depth: distance from position of test point to top of soil column; $\theta_{\text {initial }}$ : volumetric moisture content before the experiment; $\theta_{\text {final }}$ : volumetric moisture content after the experiment; $\Delta W$ : water storage at various depths, $\Delta \mathrm{W}=($ testing depth $\mathrm{n}-$ testing depth $\mathrm{n}-1) \times\left(\theta_{\text {final }}-\theta_{\text {initial }}\right)$; “- ": eliminated value which is negative because of the measurement error.

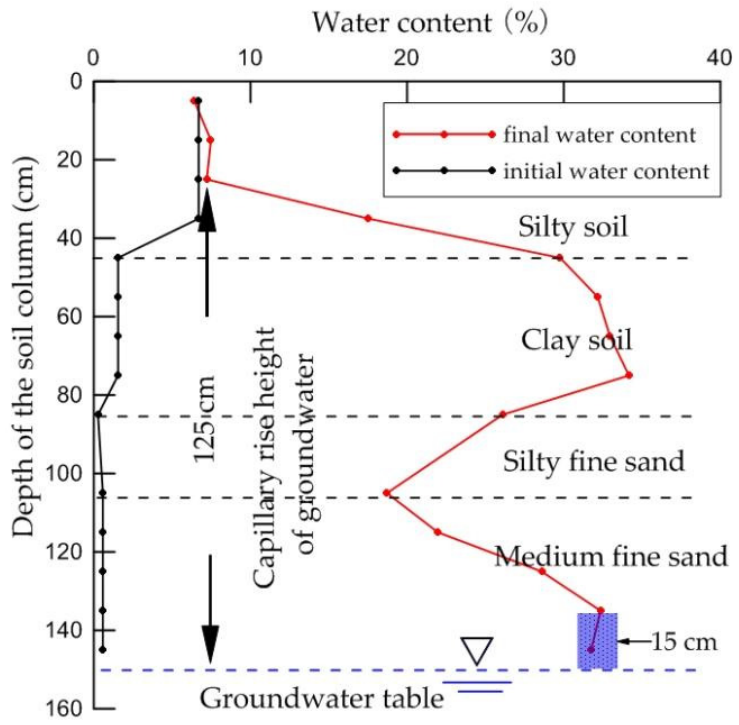

Figure 9. Comparison of initial water content and final water content.

It can be concluded that the finer-grained formation affects the capillary height and rate from Figure 10. Region ' $\mathrm{A}$ ' means the wetting front moved from medium fine sand to silty fine sand. It can be seen from the red points in region ' $A$ ' that when the wetting front passes through the interface of medium fine sand and silty fine sand, there is an obvious stagnation and then a rapid rise. Region ' $\mathrm{B}$ ' means the wetting front moved from the silty fine sand to clay soil. It can be seen from region ' $\mathrm{B}$ ' that after the wetting front passes through the interface between silty sand and clay, it continues to rise for a while (yellow points) before it comes to an obvious stagnation and then rapidly rises again (red points). The two regions have a common rule in the curve, that is, the wetting front has a short delay in the transition from coarse-grained to fine-grained lithology, and the wetting-front rate increases after entering into fine-grained lithology, in which the variation of region ' $\mathrm{A}$ ' is more obvious. This phenomenon shows that the different lithology interface hinders the water migration, and the more significant the difference is between the upper and lower soil lithology, the greater is the influence. 


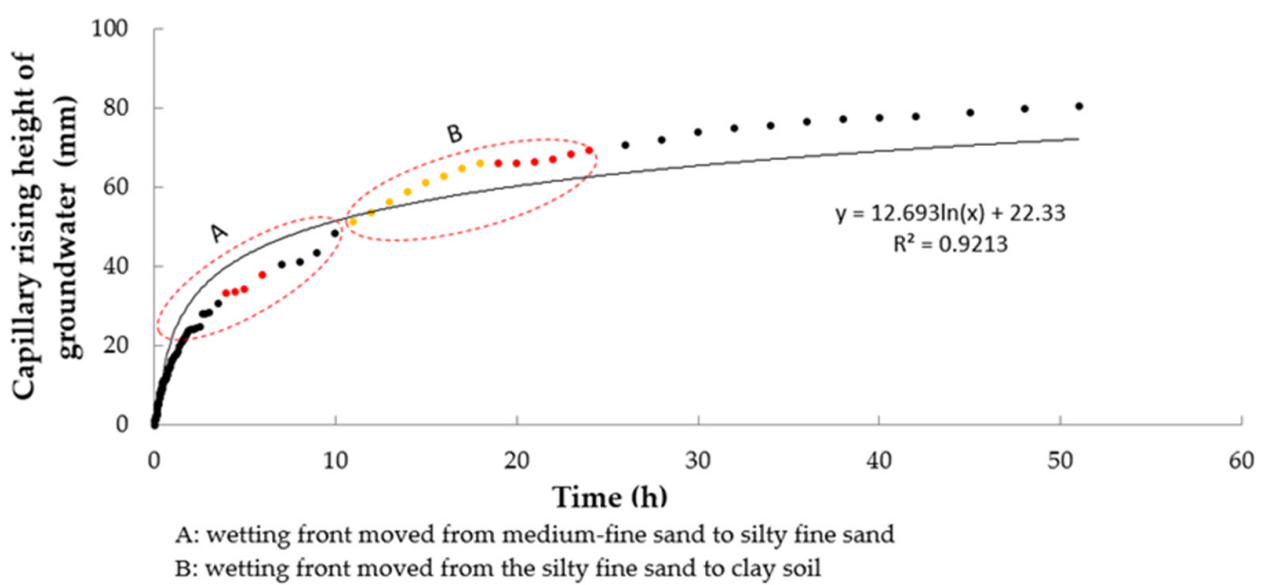

Figure 10. The accumulated height curve of wetting front increases with time in the early stage of the experiment.

\subsection{Water Release Process in Layered Vadose Zone}

In order to study the influence of the vadose zone multi-layer structure on maintaining the ecological effect under the condition of groundwater drawdown in a natural vegetation area, the water-release experiment was carried out from 17 to 24 October 2020, based on the capillary-water rising test. The water in the Mariotte's bottle was drained and used to measure the drainage during the release experiment.

Timing and recording the drainage should be started once the soil column drained water to the Mariotte's bottle. At 21:30 on the 17th, Trime was used to test the water content of the initial soil profile, and drainage began at 23:25. At the same time, the water content of the soil-column section was measured by Trime, and the drainage process ended at $08: 45$ on the 24th, with a cumulative time of $9200 \mathrm{~min}$. According to the curve of cumulative drainage and time, the drainage rate decreased with the increase of time and the cumulative drainage recorded by the Mariotte's bottle was $111 \mathrm{~mm}$ (Figure 11).

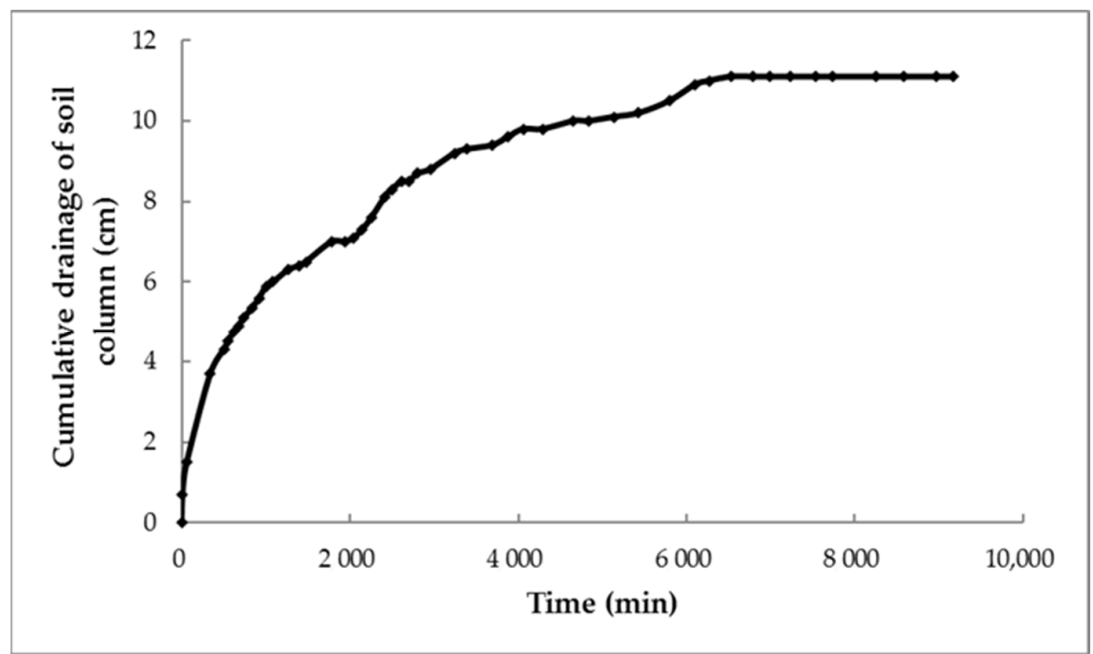

Figure 11. The cumulative drainage of soil column changes with time.

It can be seen from Figure 12 that the water content of medium fine sand and silty fine sand changed obviously after the water release, whereas the water content of clay soil and silty soil changed inconspicuously, with the clay soil especially keeping high water content. The water content below the silty fine sand dropped significantly in $11 \mathrm{~h}$ (from 21:30 17th to $08: 3018$ th), and in the following $24 \mathrm{~h}$, the decreasing rate of water content below the silty fine sand slowed. The moisture distribution of the soil profile was tested respectively again, 
at 09:00 on the 21st, 22nd and 24th. Since the water content distribution of three times had no noticeable change, the water-release test was finished. According to test results by Trime, the water-holding capacity was $340.21 \mathrm{~mm}$ (including the amount of water supplied by the Mariotte's bottle and the previously held by the previous soil column) in the soil column before water releasing, and $305.09 \mathrm{~mm}$ after water releasing (Table 3). Therefore, the total water-releasing capacity was $35.12 \mathrm{~mm}$ (the cumulative drainage recorded by the Mariotte's bottle was $111 \mathrm{~mm}$, including $75.88 \mathrm{~mm}$ of water in the filter and the aquifer), in which the medium fine sand and silty fine sand layer contributed $35.06 \mathrm{~mm}$, accounting for $99.83 \%$ in the drainage.

\subsection{Available Water Content of Soil Column after the Water-Releasing Experiment}

According to the experiment results in this paper, the water content of the whole soil column was still $305.09 \mathrm{~mm}$ (Table 3) according to the water content of the soil profile that was measured at 09:00 on 24 October. However, the available water content of the soil column after water release still needs to be discussed. It is well known that not all of the water in the soil can be used by vegetation, and the available water content is determined by the field capacity and the permanent wilting point [35-38]. According to the method in reference [39], when the soil pressure head is $-1.5 \mathrm{MPa}$, the corresponding water content is at permanent wilting point. In this study, hydrus-1D software was used to fit the soil water characteristic curves of four different lithologies according to the neural network prediction model, as shown from Figure 13. According to the soil water characteristic curves, the corresponding permanent wilting point was determined, and the permanent wilting points of clay, silty fine sand and medium fine sand are $12.47 \%, 12.37,6.51 \%$ and $4.88 \%$ (Table 4 ), respectively. The water content of the soil-column section after releasing water subtracts the wilting water content of the corresponding soil, and the remaining water is available for vegetation. The available water content of each testing depth in soil column after the water-releasing experiment are shown from Table 5, and the available water storage is $182.54 \mathrm{~mm}$, which can be used by vegetation.

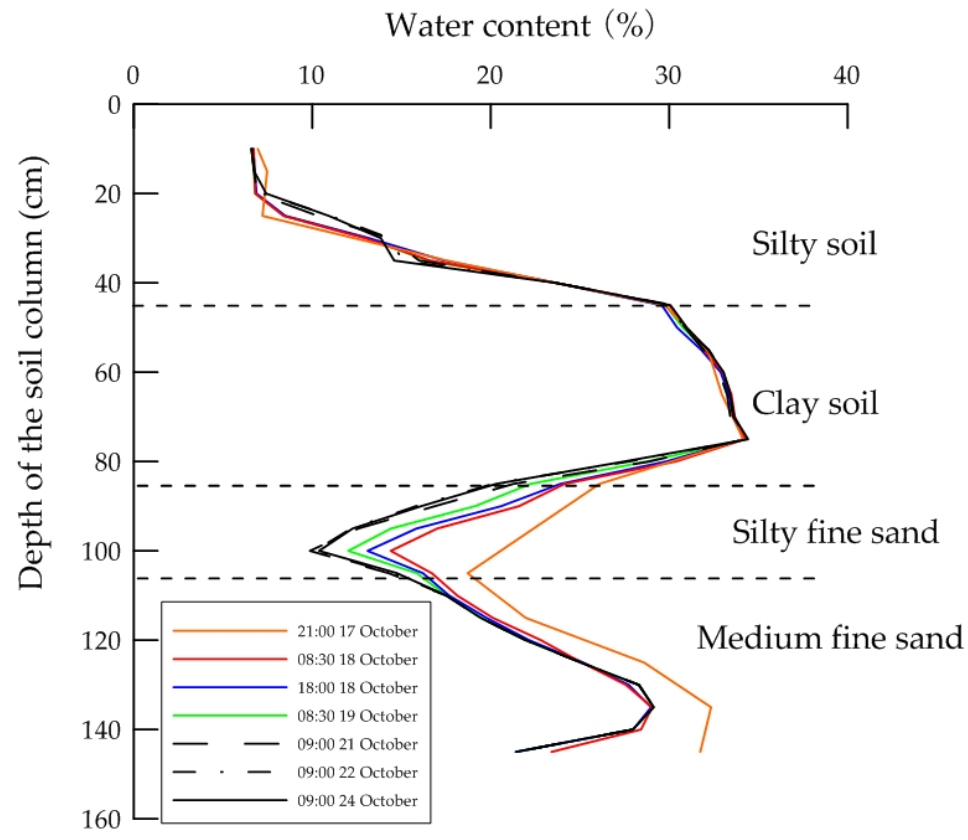

Figure 12. Variation curve of water content at different times after water release from soil column. 
Table 3. Water holding capacity of soil column before and after the water-releasing experiment.

\begin{tabular}{|c|c|c|c|c|c|}
\hline Testing Depth (cm) & Lithology & $\theta_{\text {initial }}(\%)$ & $\Delta \mathrm{W} 1(\mathrm{~mm})$ & $\theta_{\text {final }}(\%)$ & $\Delta \mathrm{W} 2(\mathrm{~mm})$ \\
\hline 10 & Silty soil & 6.94 & 6.94 & 6.60 & 6.60 \\
\hline 15 & Silty soil & 7.47 & 3.73 & 6.74 & 3.37 \\
\hline 20 & Silty soil & 7.34 & 3.67 & 7.42 & 3.71 \\
\hline 25 & Silty soil & 7.21 & 3.60 & 10.93 & 5.47 \\
\hline 30 & Silty soil & 12.37 & 6.18 & 13.85 & 6.92 \\
\hline 35 & Silty soil & 17.52 & 8.76 & 14.59 & 7.29 \\
\hline 40 & Silty soil & 23.64 & 11.82 & 23.64 & 11.82 \\
\hline 45 & Clay soil & 29.76 & 14.88 & 30.07 & 15.04 \\
\hline 50 & Clay soil & 30.96 & 15.48 & 30.98 & 15.49 \\
\hline 55 & Clay soil & 32.17 & 16.08 & 32.19 & 16.09 \\
\hline 60 & Clay soil & 32.56 & 16.28 & 33.05 & 16.52 \\
\hline 65 & Clay soil & 32.95 & 16.47 & 33.43 & 16.72 \\
\hline 70 & Clay soil & 33.55 & 16.78 & 33.64 & 16.82 \\
\hline 75 & Clay soil & 34.16 & 17.08 & 34.42 & 17.21 \\
\hline 80 & Clay soil & 30.12 & 15.06 & 27.46 & 13.73 \\
\hline 85 & Silty fine sand & 26.09 & 13.05 & 20.30 & 10.15 \\
\hline 90 & Silty fine sand & 24.25 & 12.12 & 16.10 & 8.05 \\
\hline 95 & Silty fine sand & 22.40 & 11.20 & 12.26 & 6.13 \\
\hline 100 & Silty fine sand & 20.55 & 10.28 & 10.38 & 5.19 \\
\hline 105 & Medium fine sand & 18.71 & 9.35 & 14.75 & 7.38 \\
\hline 110 & Medium fine sand & 20.33 & 10.17 & 17.51 & 8.76 \\
\hline 115 & Medium fine sand & 21.96 & 10.98 & 19.44 & 9.72 \\
\hline 120 & Medium fine sand & 25.27 & 12.64 & 21.96 & 10.98 \\
\hline 125 & Medium fine sand & 28.59 & 14.29 & 25.05 & 12.53 \\
\hline 130 & Medium fine sand & 30.47 & 15.23 & 28.30 & 14.15 \\
\hline 135 & Medium fine sand & 32.35 & 16.17 & 29.13 & 14.57 \\
\hline 140 & Medium fine sand & 32.04 & 16.02 & 27.96 & 13.98 \\
\hline 145 & Medium fine sand & 31.74 & 15.87 & 21.44 & 10.72 \\
\hline Water storage & & & 340.21 & & 305.09 \\
\hline
\end{tabular}

Testing depth: distance from position of test point to top of soil column; $\theta_{\text {initial }}$ : volumetric moisture content before the experiment; $\theta_{\text {final }}$ : volumetric moisture content after the experiment; $\Delta \mathrm{W} 1$ : initial water storage at various depths, $\Delta \mathrm{W} 1=\left(\right.$ testing depth $_{\mathrm{n}}-$ testing depth $\left._{\mathrm{n}-1}\right) \times \theta_{\text {initial-n }} ; \Delta \mathrm{W} 2$ : final water storage at various depths, $\Delta \mathrm{W} 2=($ testing depth $\mathrm{n}-$ testing depth $\mathrm{n}-1) \times \theta_{\text {final-n }}$
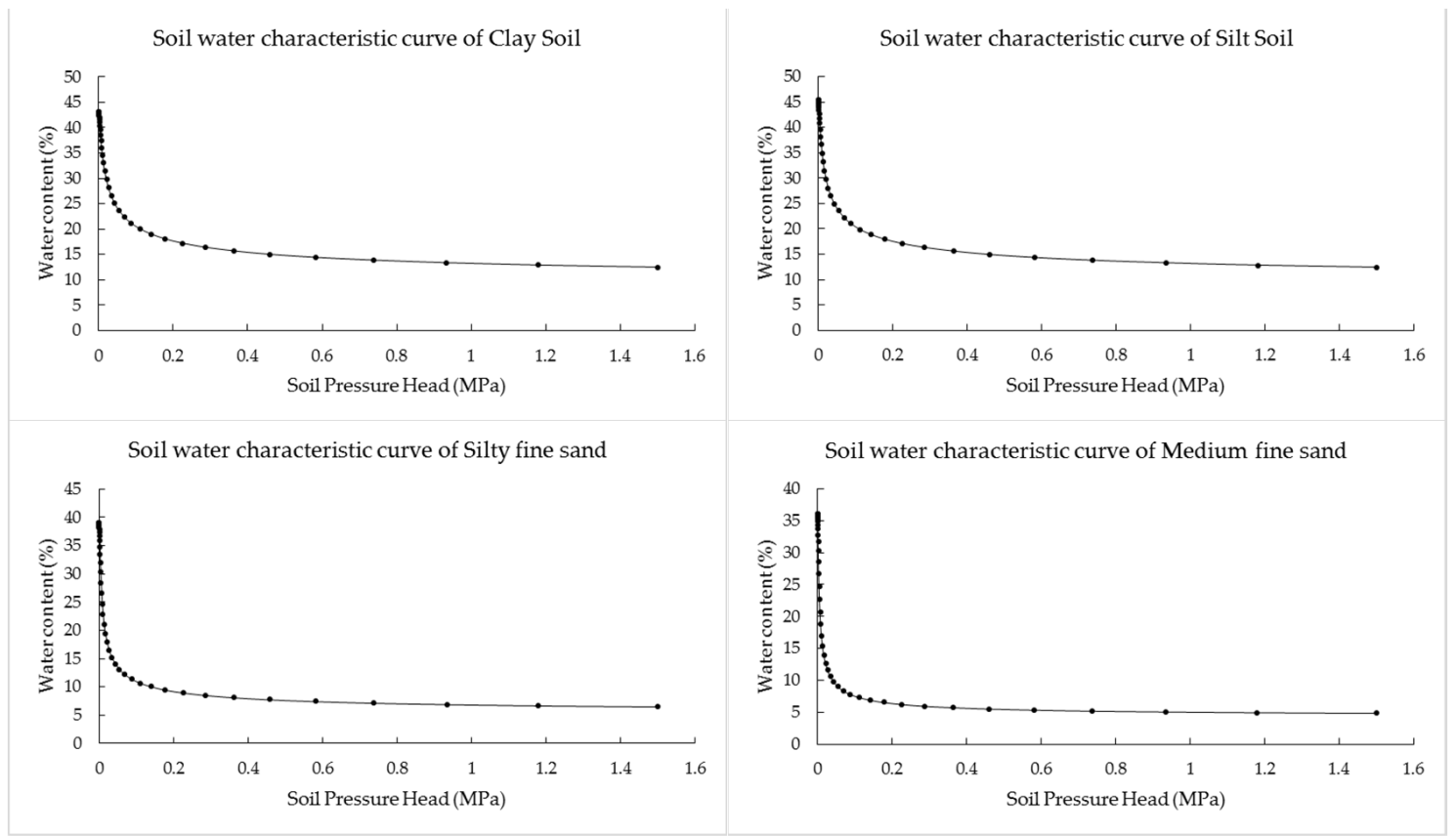

Figure 13. Soil water characteristic curve fitted by Hydrus-1D. 
Table 4. Fitting parameters and permanent wilting point of the different soils.

\begin{tabular}{|c|c|c|c|c|c|c|c|}
\hline \multirow{2}{*}{ Lithology } & \multicolumn{6}{|c|}{ Fitting Parameters } & \multirow{2}{*}{ Permanent Wilting Point ( $\%)$} \\
\hline & Qr & Qs & Alpha $(1 / \mathrm{cm})$ & $\mathbf{n}$ & Ks (cm/days) & 1 & \\
\hline Clay Soil & 0.0813 & 0.431 & 0.0141 & 1.3895 & 8.65 & 0.5 & 12.47 \\
\hline Silty Soil & 0.0804 & 0.4536 & 0.0171 & 1.3884 & 20.21 & 0.5 & 12.37 \\
\hline Silty fine sand & 0.0496 & 0.3904 & 0.0313 & 1.5032 & 49.33 & 0.5 & 6.51 \\
\hline Medium Fine sand & 0.0425 & 0.3603 & 0.0401 & 1.6131 & 60.66 & 0.5 & 4.88 \\
\hline
\end{tabular}

Qr: residual water content; Qs: saturated water content; Ks: saturated hydraulic conductivity; Alpha, $\mathrm{n}$ and l: empirical coefficients affecting the shape of the hydraulic functions in HYDRUS.

Table 5. Available water content of soil column after the water-releasing experiment.

\begin{tabular}{|c|c|c|c|c|c|c|}
\hline Testing Depth (cm) & Lithology & $\theta_{\text {final }}(\%)$ & $\Delta \mathrm{W} 2(\mathrm{~mm})$ & $\theta_{\text {pwp }}(\%)$ & $\theta_{\text {available }}(\%)$ & $\Delta \mathrm{W} 3(\mathrm{~mm})$ \\
\hline 10 & Silty soil & 6.60 & 6.60 & 12.37 & - & - \\
\hline 15 & Silty soil & 6.74 & 3.37 & 12.37 & - & - \\
\hline 20 & Silty soil & 7.42 & 3.71 & 12.37 & - & - \\
\hline 25 & Silty soil & 10.93 & 5.47 & 12.37 & 0.93 & - \\
\hline 30 & Silty soil & 13.85 & 6.92 & 12.37 & 3.85 & 0.74 \\
\hline 35 & Silty soil & 14.59 & 7.29 & 12.37 & 4.59 & 1.11 \\
\hline 40 & Silty soil & 23.64 & 11.82 & 12.37 & 13.64 & 5.64 \\
\hline 45 & Clay soil & 30.07 & 15.04 & 12.47 & 20.07 & 8.80 \\
\hline 50 & Clay soil & 30.98 & 15.49 & 12.47 & 20.98 & 9.26 \\
\hline 55 & Clay soil & 32.19 & 16.09 & 12.47 & 22.19 & 9.86 \\
\hline 60 & Clay soil & 33.05 & 16.52 & 12.47 & 23.05 & 10.29 \\
\hline 65 & Clay soil & 33.43 & 16.72 & 12.47 & 23.43 & 10.48 \\
\hline 70 & Clay soil & 33.64 & 16.82 & 12.47 & 23.64 & 10.59 \\
\hline 75 & Clay soil & 34.42 & 17.21 & 12.47 & 24.42 & 10.98 \\
\hline 80 & Clay soil & 27.46 & 13.73 & 12.47 & 17.46 & 7.50 \\
\hline 85 & Silty fine sand & 20.30 & 10.15 & 6.51 & 10.30 & 6.90 \\
\hline 90 & Silty fine sand & 16.10 & 8.05 & 6.51 & 6.10 & 4.80 \\
\hline 95 & Silty fine sand & 12.26 & 6.13 & 6.51 & 2.26 & 2.88 \\
\hline 100 & Silty fine sand & 10.38 & 5.19 & 6.51 & 0.38 & 1.94 \\
\hline 105 & Medium fine sand & 14.75 & 7.38 & 4.88 & 4.75 & 4.94 \\
\hline 110 & Medium fine sand & 17.51 & 8.76 & 4.88 & 7.51 & 6.32 \\
\hline 115 & Medium fine sand & 19.44 & 9.72 & 4.88 & 9.44 & 7.28 \\
\hline 120 & Medium fine sand & 21.96 & 10.98 & 4.88 & 11.96 & 8.54 \\
\hline 125 & Medium fine sand & 25.05 & 12.53 & 4.88 & 15.05 & 10.09 \\
\hline 130 & Medium fine sand & 28.30 & 14.15 & 4.88 & 18.30 & 11.71 \\
\hline 135 & Medium fine sand & 29.13 & 14.57 & 4.88 & 19.13 & 12.13 \\
\hline 140 & Medium fine sand & 27.96 & 13.98 & 4.88 & 17.96 & 11.54 \\
\hline 145 & Medium fine sand & 21.44 & 10.72 & 4.88 & 11.44 & 8.28 \\
\hline Water storage & & & 305.09 & & & 182.54 \\
\hline
\end{tabular}

Testing Depth: distance from position of test point to top of soil column; $\theta_{\text {final }}$ : volumetric moisture content after the experiment; $\theta_{\text {pwp }}$ : permanent wilting point, when the soil moisture content is lower than $\theta_{\text {pwp }}$, the water will not be absorbed by the vegetation; $\theta_{\text {available }}$ available volumetric moisture content, $\theta_{\text {final }}-\theta_{\text {pwp }} ; \Delta \mathrm{W} 2$ : final water

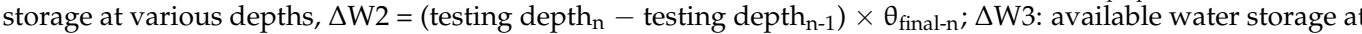
various depths, $\Delta \mathrm{W} 3=\left(\text { testing depth } n-\text { testing depth }{ }_{n-1}\right)^{*} \theta_{\text {available-n }} ; "$-": $^{\prime \prime}$ eliminated value which is negative.

\section{Discussion}

\subsection{Water Consumption of Typical Vegetation in Arid Area}

The arid area in northwest China is characterized by sparse precipitation, large potential evapotranspiration and low soil-moisture content, so the xerophytic vegetation depends on groundwater growth. There are many studies on water consumption of typical plants in different watersheds in arid areas of northwest China. Generally speaking, the transpiration water consumption of different plants is quite different in the growing season. The transpiration of aquatic plants such as Phragmites australis and Tamarix ramosissima in the riparian zone is higher than that of xerophytes such as Apocynum venetum, Nitraria, Populus euphratica and Haloxylon. Moreover, the water consumption of the same vegetation in the growing season is different under different groundwater depths. With the increase of groundwater depth, the water available to the roots of desert plants decreases. Plants can reduce water consumption by regulating physiological characteristics such as stomatal conductance. The growth period of vegetation in arid areas is from April to September. Moreover, in the same growing season, the plant evapotranspiration can be reduced by about $50 \%$ when the suitable ecological groundwater depth decreases to the limit of eco- 
logical groundwater depth. Using the Tardieu-Davies model, Zhang et al. [40] calculated water consumption during the growing season under different ecological groundwater depths in the Shiyang River Basin. Under suitable ecological groundwater depths, the transpiration of Phragmites australis and Tamarix chinensis were $1292 \mathrm{~mm}$ and $1147 \mathrm{~mm}$, respectively, during the growing season; and the transpiration of Haloxylon ammodendron was 279 mm; and Halocnemum, Apocynum venetum, Nitraria tangutorum and Populus euphratica were $940 \mathrm{~mm}, 913 \mathrm{~mm}, 534 \mathrm{~mm}$ and $448 \mathrm{~mm}$, respectively. However, under the extreme ecological groundwater depth, the transpiration of all vegetation decreased to some extent. The transpiration of Phragmites australis and Tamarix chinensis were $1050 \mathrm{~mm}$ and $999 \mathrm{~mm}$, respectively; the transpiration of Haloxylon ammodendron was $130 \mathrm{~mm}$; and that of Halocnemum, Apocynum venetum, Nitraria tangutorum and Populus euphratica were $706 \mathrm{~mm}, 686 \mathrm{~mm}, 345 \mathrm{~mm}$ and $298 \mathrm{~mm}$, respectively.

\subsection{Influence of Multi-Layer Structure of Vadose Zone on Maintaining Ecological Effect of Groundwater}

After the groundwater level drops, the moisture content of the soil above the water table can still maintain the vegetation to a certain extent. Taking Haloxylon ammodendron as an example, the water-supply time of the layer structure vadose zone was analyzed after the groundwater level dropped. Under the condition of suitable ecological groundwater depth, the water consumption of Haloxylon ammodendron in the growing season (from April to September) was $279 \mathrm{~mm}$, which is a typical arid vegetation in the arid area of northwest China. In contrast, the water consumption of vegetation decreased by about $50 \%$ (that is $130.0 \mathrm{~mm}$ ) under the extreme ecological groundwater depth. Therefore, according to the experimental results in this paper (Table 5), it can be concluded that under ideal conditions, the water stored in the stratum $(182.54 \mathrm{~mm})$ can maintain a growing season (6 months) of Haloxylon ammodendron after the groundwater level drops. In particular, the existence of a clay soil structure makes the soil profile hold higher water content after the water level drops, which has a significant positive effect on maintaining the benign development of land surface ecology.

\section{Conclusions}

(1) According to the field survey, it was found that the structure of the vadose zone of natural vegetation in arid areas is a multi-layered structure, which has a positive effect on maintaining ecology. Moreover, the clay soil layer in the vadose zone will make the groundwater capillary rise higher $(140 \mathrm{~cm})$, making it easier for the roots of the vegetation on the ground to obtain water;

(2) When the groundwater level drops, the water-holding capacity of the multi-layered vadose zone will continue to maintain high water content for the survival of surface vegetation in a certain time and range. Combined with the ecological water consumption of Haloxylon ammodendron in the growing season and indoor soil-column test, the available water held by multi-layered structure of the vadose zone can maintain Haloxylon ammodendron to survive in a growing season (6 months) after the groundwater level drops;

(3) The research results can provide a scientific basis for the fine management of groundwater in arid regions. As we all know, artificial water delivery is an effective means to control ecological problems, but the period and the amount of water delivery have been debated by a wide range of scholars. The research calculated the available water held by the multi-layered vadose zone and the survival time of the typical vegetation when the groundwater depth drops below the ecological groundwater level. It will provide a scientific basis for the optimization of an ecological water-delivery period and water quantity;

(4) Based on the above research, it is recommended to investigate the structure of the vadose zone in natural vegetation areas in arid areas to carry out the district manage- 
ment of ecological protection [41-44], realize refined management of groundwater and improve water-resource utilization efficiency.

Author Contributions: Conceptualization, G.Z.; methodology, H.C.; software, H.C.; validation, J.W., Q.W. and X.L.; formal analysis, H.C.; investigation, J.W., Q.W. and H.C.; data curation, G.Z.; writing-original draft preparation, H.C.; writing—review and editing, X.L.; visualization, H.C.; supervision, X.L.; project administration, G.Z.; funding acquisition, G.Z., Q.W. and H.C. All authors have read and agreed to the published version of the manuscript.

Funding: This research was funded by National Key R\&D Program of China (Grant No. 2017YFC0406106), the National Natural Science Foundation of China (Grant No. 41807217), and the Key Innovative Research Project of National Special Fundamental Research Funds (Grant No. JYYWF20180403).

Institutional Review Board Statement: Not applicable.

Informed Consent Statement: Not applicable.

Data Availability Statement: The data presented in this study are available on request from the corresponding author.

Conflicts of Interest: The authors declare no conflict of interest.

\section{References}

1. Liu, M.; Liu, P.; Guo, Y.; Wang, Y.; Geng, X.; Nie, Z.; Yu, Y. Change-Point Analysis of Precipitation and Drought Extremes in China over the Past 50 Years. Atmosphere 2019, 11, 11. [CrossRef]

2. Liu, M.; Shen, Y.; Qi, Y.; Wang, Y.; Geng, X. Changes in Precipitation and Drought Extremes over the Past Half Century in China. Atmosphere 2019, 10, 203. [CrossRef]

3. Chen, M.; Zhang, Q.; Wang, Y.; Yan, L.; Deng, W. Critical depth of recharge of the vegetation by groundwater in the West Liaohe Plain. Adv. Water Sci. 2019, 30, 24-33. [CrossRef]

4. Wang, W.; Gong, C.; Zhang, Z.; Chen, L. Research Status and Prospect of the Subsurface Hydrology and Ecological Effect in Arid Regions. Adv. Earth Sci. 2018, 33, 702-718. [CrossRef]

5. Li, F.; Wang, Y.; Zhao, Y.; Chen, X. Modelling the response of vegetation restoration to changes in groundwater level, based on ecologically suitable groundwater depth. Hydrogeol. J. 2018, 26, 2189-2204. [CrossRef]

6. Johansen, O.M.; Andersen, D.K.; Ejrnæs, R.; Pedersen, M.L. Relations between vegetation and water level in groundwater dependent terrestrial ecosystems (GWDTEs). Limnologica 2018, 68, 130-141. [CrossRef]

7. Cao, L.; Nie, Z.; Liu, M.; Wang, L.; Wang, J.; Wang, Q. The Ecological Relationship of Groundwater-Soil-Vegetation in the Oasis-Desert Transition Zone of the Shiyang River Basin. Water 2021, 13, 1642. [CrossRef]

8. Hu, S.; Ma, R.; Sun, Z.; Ge, M.; Zeng, L.; Huang, F.; Bu, J.; Wang, Z. Determination of the optimal ecological water conveyance volume for vegetation restoration in an arid inland river basin, northwestern China. Sci. Total Environ. 2021, 788, 147775. [CrossRef]

9. Huang, F.; Zhang, D.; Chen, X. Vegetation Response to Groundwater Variation in Arid Environments: Visualization of Research Evolution, Synthesis of Response Types, and Estimation of Groundwater Threshold. Int. J. Environ. Res. Public Health 2019, 16, 1849. [CrossRef]

10. Cheng, G.; Liu, D.; Wen, L.; Liu, H.; Dong, S.; Wang, L. Effects of Groundwater and Soil Chemical Properties on Distribution of Natural Vegetation around Playa. Arid Zone Res. 2019, 36, 85-94. [CrossRef]

11. Jia, L.; Guo, Z.; Long, Y.; Guo, K.; Liao, Z. Rearch advances in ecological groundwater level in arid areas. Ecol. Sci. 2015, 34, 187-193. [CrossRef]

12. Taufik, M.; Veldhuizen, A.A.; Wösten, J.H.M.; Lanen, H.A.J. Exploration of the importance of physical properties of Indonesian peatlands to assess critical groundwater table depths, associated drought and fire hazard. Geoderma 2019, 347, 160-169. [CrossRef]

13. Zhang, C.; Shao, J.; Li, C.; Cui, Y. A study on the ecological groundwater table in the North China plain. J. Jilin Univ. Earth Sci. Ed. 2003, 33, 323-326. [CrossRef]

14. Eamus, D.; Zolfaghar, S.; Villalobos-Vega, R.; Cleverly, J.; Huete, A. Groundwater-dependent ecosystems: Recent insights from satellite and field-based studies. Hydrol. Earth Syst. Sci. 2015, 19, 4229-4256. [CrossRef]

15. Liao, Z.; Ma, Z.; Cheng, S.; Xie, X.; He, H. Dominant critical water level of groundwater and its determing method. Water Resour. Hydropower Eng. 2018, 49, 26-32. [CrossRef]

16. Huang, F.; Zhang, Y.; Zhang, D.; Chen, X. Environmental groundwater depth for groundwater-dependent terrestrial ecosystems in arid/semiarid regions: A review. Int. J. Environ. Res. Public Health 2019, 16, 763. [CrossRef] [PubMed]

17. Zhu, L.; Xu, G.; Li, Y.; Tang, L.; Niu, Z. Relationships among plant species diversity, biomass, and the groundwater table in the Hailiutu River basin. Acta Ecol. Sin. 2017, 37, 1912-1921. [CrossRef]

18. Wang, S.; Wu, B.; Yang, P.; Li, X.; Dong, X. Determination of the Ecological Groundwater Depth Considering Ecological Integrity over Oasis Irrigation Areas in the Yanqi Basin. Resour. Sci. 2011, 33, 422-430. 
19. Chui, T.F.M.; Low, S.Y.; Liong, S. An ecohydrological model for studying groundwater-vegetation interactions in wetlands. J. Hydrol. 2011, 409, 291-304. [CrossRef]

20. Jiang, L.; Shang, S.; Mao, X. Simulation on the impact of the groundwater table on evapotranspiration of a riparian forest in arid region. J. Tsinghua Univ. (Sci. Tech.) 2013, 53, 601-605, 612. [CrossRef]

21. Zhang, Y.; Chen, X.; Gao, M.; Liu, X. Meta-analysis of ecological depth to groundwater table and its influencing factors in arid region of northwest China. South-to-North Water Transf. Water Sci. Technol. 2020, 18, 57-65. [CrossRef]

22. Sheng, J.; Qiao, Y.; Liu, H.; Zhai, Z.; Guo, Y. A Study on the Root System of Haloxylon Aammodendron (C.A.Mey.) Bunge. Acta Agrestia Sin. 2004, 12, 91-94. [CrossRef]

23. Zhou, H. Review of studies on the relationship between soil water movement and energyand their driving forces in the vadose zone of arid regions. Acta Ecol. Sin. 2019, 39, 6586-6597. [CrossRef]

24. Zhou, H.; Zhao, W. Soil physical characteristics of shallow vadose zone and modeling its effects on upward capillary rise of groundwater in an arid-desert area. Chin. J. Appl. Ecol. 2019, 30, 2999-3009. [CrossRef]

25. Huang, M.; Barbour, S.L.; Elshorbagy, A.; Zettl, J.D.; Si, B.C. Infiltration and drainage processes in multi-layered coarse soils. Can. J. Soil Sci. 2011, 91, 169-183. [CrossRef]

26. Zornberg, J.G.; Bouazza, A.; McCartney, J.S. Geosynthetic capillary barriers: Current state of knowledge. Geosynth. Int. 2010, 17, 273-300. [CrossRef]

27. Shi, W.; Shen, B.; Wang, Z.; Wang, W. Maximum height of upward capillary water movement in layered soil. Agric. Res. Arid Areas 2007, 25, 94-97. [CrossRef]

28. Cui, H.; Zhang, B.; Feng, X.; Gao, Y. Soil water-holding properties of different soil body configuration. Agric. Res. Arid Areas 2016, 34, 1-5. [CrossRef]

29. Ge, J.; Huang, D.; Gao, X.; Tang, J.; Shen, H. Water Retention Capacity of Drained Soil Columns with Grained Layers. Southwest China J. Agric. Sci. 2019, 32, 2126-2132. [CrossRef]

30. Chunyu, X.; Huang, F.; Xia, Z.; Zhang, D.; Chen, X.; Xie, Y. Assessing the Ecological Effects of Water Transport to a Lake in Arid Regions: A Case Study of Qingtu Lake in Shiyang River Basin, Northwest China. Int. J. Environ. Res. Public Health 2019, 16, 145. [CrossRef]

31. Huang, F.; Chunyu, X.; Zhang, D.; Chen, X.; Ochoa, C.G. A framework to assess the impact of ecological water conveyance on groundwater-dependent terrestrial ecosystems in arid inland river basins. Sci. Total Environ. 2020, 709, 136155. [CrossRef]

32. Huang, F.; Ochoa, C.G.; Chen, X.; Zhang, D. Modeling oasis dynamics driven by ecological water diversion and implications for oasis restoration in arid endorheic basins. J. Hydrol. 2021, 593, 125774. [CrossRef]

33. Qian, J.; Chang, J.; Ma, H.; Ran, X.; Wang, Y. Comprehensive Water Resources Planning of Minqin County; Lanzhou University: Lanzhou, China, 2013; Unpublished work.

34. Shao, M.; Wang, Q.; Huang, M. Soil Physics; Higher Education Press: Beijing, China, 2006.

35. Chen, C.; Zhou, H.; Shang, J.; Hu, K.; Ren, T. Estimation of soil water content at permanent wilting point using hygroscopic water content. Eur. J. Soil Sci. 2020, 71, 392-398. [CrossRef]

36. Taşan, S.; Demir, Y. Comparative Analysis of MLR, ANN, and ANFIS Models for Prediction of Field Capacity and Permanent Wilting Point for Bafra Plain Soils. Commun. Soil Sci. Plant Anal. 2020, 51, 604-621. [CrossRef]

37. Ostovari, Y.; Asgari, K.; Cornelis, W. Performance evaluation of pedotransfer functions to predict field capacity and perma- nent wilting point using UNSODA and HYPRES Dataset. Arid Land Res. Manage. 2015, 29, 383-398. [CrossRef]

38. Assi, A.T.; Blake, J.; Mohtar, R.H.; Braudeau, E. Soil aggregates structure-based approach for quantifying the field capacity, permanent wilting point and available water capacity. Irrig. Sci. 2019, 19, 3805-3816. [CrossRef]

39. Wiecheteck, L.H.; Giarola, N.F.B.; de Lima, R.P.; Tormena, C.A.; Torres, L.C.; de Paula, A.L. Comparing the classical permanent wilting point concept of soil $(-15,000 \mathrm{hPa})$ to biological wilting of wheat and barley plants under contrasting soil textures. Agric. Water Manag. 2020, 230, 105965. [CrossRef]

40. Zhang, Y.; Chen, X.; Gao, M.; Liu, X. Simulation of transpiration for typical xeromorphic plants in inland arid region of Northwestern China. Acta Ecol. Sin. 2021, 41, 7751-7762. [CrossRef]

41. Wang, X.; Shao, J.; Cui, Y.; Zhang, Q. Application of a Surrogate Model for a Groundwater Numerical Simulation Model for Determination of the Annual Control Index of the Groundwater Table in China. Sustainability 2020, 12, 5752. [CrossRef]

42. Wang, J.; Zhang, G.; Yan, M.; Tian, Y.; Wang, Q. Index weight analysis of groundwater function evaluation and zoning system in arid areas. Trans. CSAE 2020, 36, 133-143. [CrossRef]

43. Wang, J.; Zhang, G.; Wang, Q.; Cui, H.; Liu, P. Construction and application of evaluation index system of groundwater ecological function in northwest arid area. Acta Geol. Sin. 2021, 95, 1573-1581. [CrossRef]

44. Wang, J.; Zhang, G.; Cui, H.; Wang, Q.; Dong, H.; Hao, J. System index attribute and application of groundwater function zoning in northwest inland area of China. J. Hydraul. Eng. 2020, 51, 796-804. [CrossRef] 